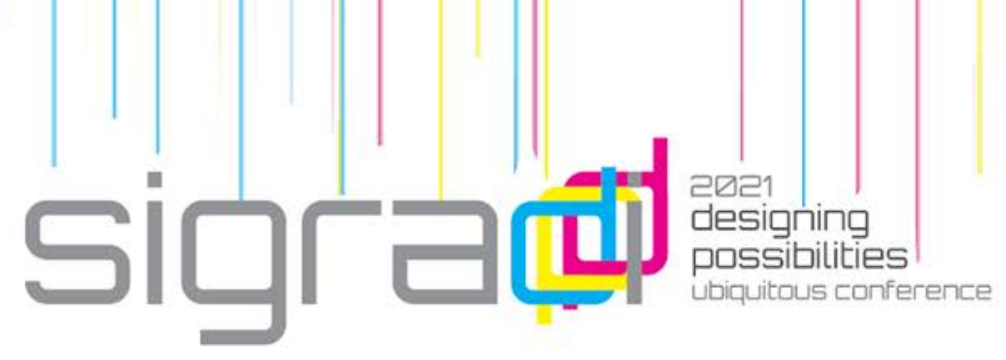

\title{
Inclusive Architecture: Landscaping Codesign in Children's Playgrounds
}

\author{
Priscila Castioni Isele ${ }^{1}$, Andréa Quadrado Mussi ${ }^{1}$ \\ ${ }^{1}$ IMED, Brasil \\ priscila.castioni@hotmail.com \\ andrea.mussi@imed.edu.br
}

\begin{abstract}
Children's playgrounds or also called playgrounds are open spaces, the basis for children's recreation. Important for the inclusion and mobility of visually impaired children in the social environment, through inclusive urban facilities that stimulate new experiences for their cognitive development. In this context, the use of Co-design with visually impaired people, in the design processes of children's playgrounds, assumes an importance for an inclusive project based on their experiences. Thus, it aimed to promote a project together, to provide more comfort and safety to users. It presents as main results as better colors, materials and types of toys for children with visual impairment to be competent in a playground including from the application of methods, tools and resources in the Co-design process.
\end{abstract}

Keywords: Co-design, Children's Playgrounds, Visually Impaired People

\section{Introdução}

Cavalvanti, Andrade e Silva (2011) defendem a projetação arquitetônica conjunta, podendo reconhecer as preferências projetuais e fortalecendo um coletivo, tendo como um dos principais objetivos a melhor identificação das necessidades dos usuários que coabitarão no local a ser projetado.

Os Projetos Colaborativos (PC) mais conhecidos como Codesing são utilizados atualmente com o propósito de melhoramentos projetuais com profissionais ou colaboradores de diversas áreas de atuação, gerando uma parceria de objetivo mútuo, atuando na arquitetura, no urbanismo, em interiores ou no paisagismo, sendo estes os mais usados pelos profissionais Arquitetos e Urbanistas.

Pessoas que nasceram ou se tornaram cegas em um curto período, não possuem um sistema de referência visual, uma imagem visual concreta. 
Portanto, para suas percepções espaciais precisam confiar em informações de outros órgãos sensoriais além da visão, como o tato, a audição e o olfato para compreender sua acessibilidade e conforto em um ambiente (Heylighen, Herssen, 2014).

As experiências multissensoriais na natureza segundo Pallasmaa (2011) são necessárias e saudáveis, promovendo integração dos sentidos onde a visão colabora com o que o corpo já sente, o aroma, o sentir das plantas, mobiliários e espaços. A Arquitetura se torna uma extensão natural, sendo suporte para a percepção dos ambientes, transmitindo a experiência da compreensão do mundo através do contato, essência e escuta na natureza.

Aos Projetos Colaborativos (PC) em espaços de lazer, as Pessoas com Deficiência Visual (PcDV) atuam principalmente com suas experiências do cotidiano, tornando-se grandes aliadas para os projetos arquitetônicos. Segundo Carneiro, Barros e Zibel (2011) a atuação das PcDv possibilitam maiores informações para adequações projetuais, sendo assim, havendo trocas de informações, experiências, histórias e um estudo aprofundado para tornar o local a ser projetado inclusivo e apropriado ao tema.

A presente pesquisa tem por objetivo aplicar as metodologias do Codesign em espaços de lazer conjunto às experiências diárias de pessoas cegas e de baixa visão através de técnicas, métodos e ferramentas aplicadas na inclusão das PcDV no processo de projeto de paisagismo. As técnicas utilizadas na pesquisa são Workshops, Passeios Acompanhados, Focus Group (FG) com entrevistas semiestruturadas e uso de plantas e maquetes táteis com uso de fabricação digital, sendo uma ferramenta para o meio de comunicação que no caso será a maquete tátil na prática do Codesign entre a projetista e PCDV. Essa pesquisa faz parte dos estudos desenvolvidos desde 2013 pelo NITA-AU (Núcleo de Inovação e Tecnologia Assistiva em Arquitetura e Urbanismo) do Omitido (Omitido, 2020).

2 Metodologiao Codesign é um processo de elaboração de projetos e produtos, aplicado na arquitetura entre os designers e os usuários, com objetivo de integrar os mesmos na elaboração dos Processos de Projeto (PP). Seus processos pressupõem que a criação conjunta favorece a um resultado adequado e mais atendível ao usuário, variando suas metodologias, ferramentas e recursos de aplicação para cada projeto (Caixeta e Fabrício, 2018). Para o projeto de Codesign de paisagismo em playground infantis, serão utilizados alguns métodos, ferramentas e recursos extraídos da revisão bibliográfica sobre o tema que serão explicados neste fragmento da pesquisa.

Os métodos, ferramentas e recursos adotados na elaboração do Projeto Colaborativo da praça OMITIDO com as PcDV foram desenvolvidos em 
etapas, realizadas por meio de Workshops com brincadeiras sensoriais, uso de fabricação digital para produzir as maquetes táteis, passeios acompanhados e Focus Groups (FG) associados às entrevistas semiestruturadas, promovendo feedbacks constantes dos usuários e estabelecendo uma participação efetiva com o projeto.

As estratégias adotadas para pesquisa se fundamentam em uma visão integral de eventos do cotidiano das PCDV, possibilitando um questionamento e compreensão do comportamento dos indivíduos sobre as dificuldades recorrentes em espaços de lazer. Informações essas que irão guiar no desenvolvimento de realização ou modificações do projeto serão resultantes das interações com os voluntários.

O local escolhido como estudo para a pesquisa é a Praça OMITIDO, inaugurada no ano de 2019, tem grande envolvimento com a sociedade recebendo famílias e escolas durante toda a semana. O Playground da praça OMITIDO contém uma área total de $98,20 \mathrm{~m}^{2}$, com um brinquedo para crianças de 03 a 13 anos.

A pesquisa será concentrada em um Projeto Colaborativo (PC) para um playground infantil da praça. O PC, foi efetuado com estudantes e professores da escola OMITIDO em Marau, com um objetivo amplo de inclusão para um design universal enfatizando na pesquisa as 05 crianças com deficiência visual da escola, abrangendo todos os usuários, características das distintas condições cognitivas e idade das crianças, se realizou através de uma proposta de projeto de um Playground inclusivo para crianças com deficiência visual por meio de cores, texturas e sons com a participação efetiva de todos os alunos.

No Projeto Colaborativo, foram aplicados três métodos, ferramentas e recursos: Workshop com brincadeiras que exploram o sentido sensorial, uso de maquetes táteis fabricadas digitalmente para melhor percepção dos ambientes e FG associados com entrevistas semiestruturadas.

Inicialmente, houve um breve conhecimento do dia a dia das crianças na escola e apresentação da projetista aos alunos, em que aconteceu individualmente na casa das crianças, com a projetista, alunos e os pais. Aconteceu também, a aplicação de Workshops com a turma inclusiva, que foram entregues nas casas das crianças, devido a pandemia, para serem aplicadas com os pais. Os quais encaminharam os resultados e discussões via áudio ou vídeo para a projetista e em seguida foram transcritas para texto. As brincadeiras foram essencialmente sensoriais, que estimulam a diferenciação de cores, sons e texturas para melhor aplicação dos mesmos no processo de projeto do Playground da praça. As brincadeiras aplicadas foram: Organizando Cores, Jogo da Memória Auditivo e Caixa Mágica das texturas. 


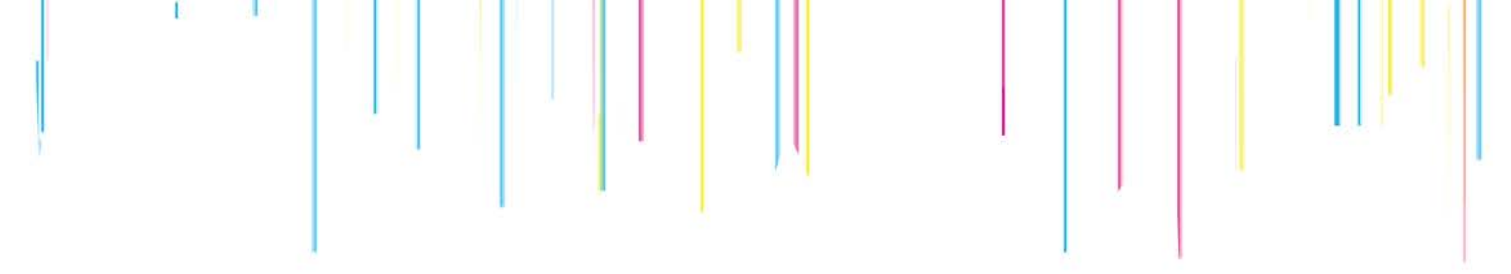

Nas metodologias preliminares do PC, houve um momento da projetista na elaboração de duas maquetes táteis fabricadas digitalmente com o uso de impressora 3D. Com a intenção de avaliar a maquete tátil fabricada digitalmente como meio de comunicação no processo de Codesign. A primeira maquete tátil foi de um espaço de lazer da escola OMITIDO (Figura 11). Lugar esse, que os estudantes já conhecem e se familiarizam e outra do Playground infantil da praça a ser requalificado.

As duas maquetes táteis foram fabricadas digitalmente, possibilitando a comunicação entre o grupo através do sensor tátil instigando a criatividade e critérios para soluções futuras do projeto. Através da impressora Sethi 3D, com sistema de FDM (Fused Deposition Modelling) localizada no laboratório de fabricação digital da OMITIDO.

Nas metodologias preliminares do projeto colaborativo com crianças, foi desenvolvido o FG online com a participação e auxílio dos responsáveis com entrevistas semiestruturadas a respeito dos métodos, ferramentas e recursos já aplicados, argumentando sobre cores, texturas e sons para aplicação no projeto. Havendo também a apresentação por parte da projetista de duas maquetes táteis fabricadas digitalmente com objetivo de instigar opiniões sobre os espaços.

Ainda nas metodologias preliminares, ocorreu um FG em conjunto à entrevistas semiestruturadas online com momentos em que o entrevistador conta com um material de apoio (maquete tátil) para debater sobre os tópicos com auxílio dos responsáveis, utilizando o uso de fabricação digital para opiniões e discussões em roda como "Alguém sentiu falta de algum brinquedo no Playground? Por que?" "Qual é a sensação da utilização da maquete tátil para a percepção dos brinquedos do Playground?" "Gostaram da utilização da maquete tátil? Por que?" gerando um conceito e diretrizes participativas que contribuiram para o projeto em que foi realizado pela projetista.

\section{$3 \quad$ Resultados e Discussões}

\subsection{Workshop com Brincadeiras}

A aplicabilidade de brincadeiras com dez crianças estudantes da escola OMITIDO, com idades entre quatro a dez anos foi utilizada como auxílio para o desenvolvimento do projeto do Playground da Praça OMITIDO. As três brincadeiras: Organizando Cores, Jogo da Memória Auditivo e Caixa Mágica foram aplicadas nas casas das crianças, com o auxílio dos pais, via internet e com transcrição de áudio para texto. 
A terceira e última brincadeira aplicada com as crianças estudantes, foi a brincadeira Caixa Mágica (Figura 03). O objetivo da terceira brincadeira foi buscar os diferentes tipos de materiais para a concepção dos brinquedos. As crianças acharam a areia, material natural, interessante e o plástico um material mais confortável e seguro para brinquedos, segundo as crianças. A madeira, ressaltada como o material menos confortável para a concepção dos brinquedos devido ser o material mais áspero como demonstra o Gráfico com percentual dos melhores materiais para os brinquedos do Playground.

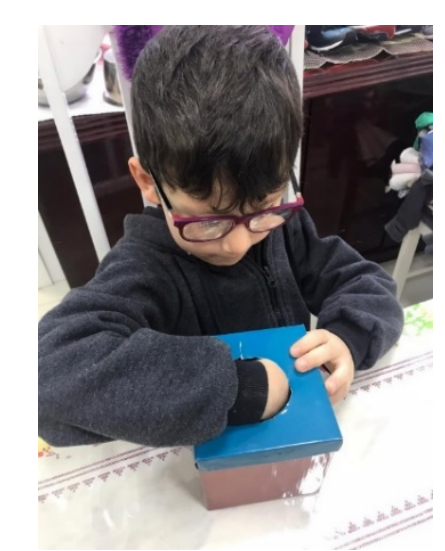

Figura 3. Imagens do participante realizando a atividade. Fonte: Participante da Pesquisa (2020).

\subsection{Maquetes Táteis}

Foram realizadas duas maquetes táteis como meio de comunicação entre a projetista e os participantes da pesquisa para melhor entendimento e aproveitamento das experiências diárias de cada participante. Inicialmente uma do playground existente na escola OMITIDO onde os participantes já conhecem e fazem a utilização do meio e outra do playground da OMITIDO, para assim, haver comparação entre as duas maquetes, instigar novas opiniões sobre o meio de comunicação e as mesmas. Onde foram aplicadas durante as metodologias do projeto de pesquisa.

\subsection{Concepção e Materiais das Maquetes}

As duas maquetes táteis foram fabricadas digitalmente, através da impressora Sethi 3D, com sistema de FDM (Fused Deposition Modelling e projetadas inicialmente pelo software Revit 2020 e após pelo software online TinkerCad. 


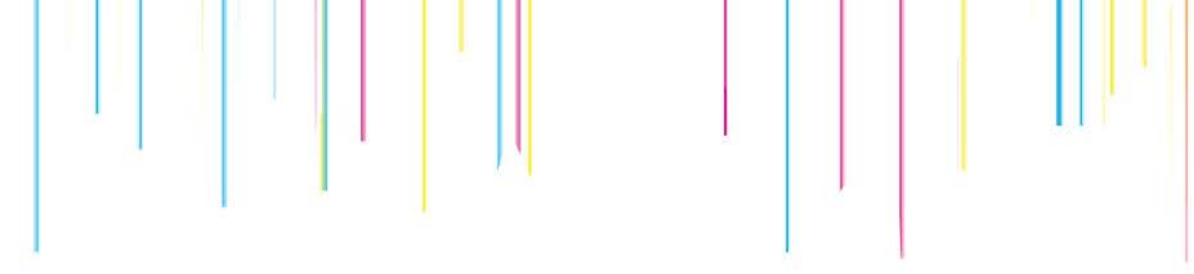

Inicialmente, as maquetes táteis foram projetadas pelo Software Revit 2020 e fabricadas em apenas dois elementos sólidos, um elemento contendo o playground da escola omitido e outro do playground da omitido em que nos dois elementos os brinquedos foram confeccionados pela impressora Sethi $3 D$, sem haver processos de montagem ou colagem, produzidos em apenas um módulo e plano cada um, havendo alguns problemas como demonstra abaixo.
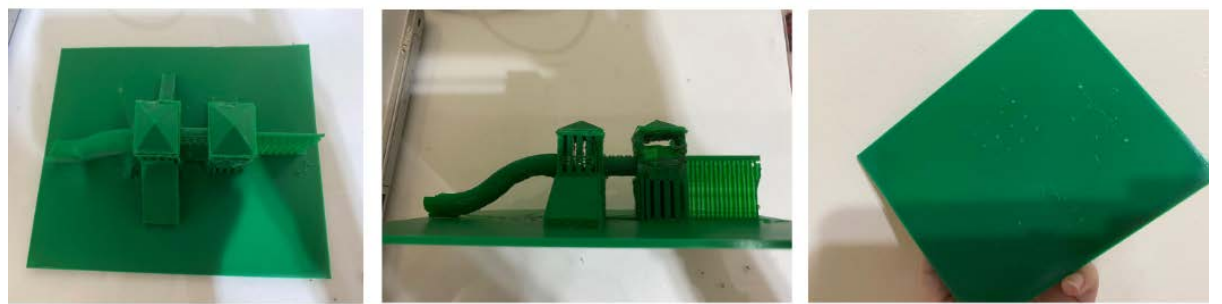

Figura 4. Maquete tátil inicial. Fonte: Autora (2020).

O principal problema das primeiras maquetes fabricadas foram as rebarbas durante a impressão, por serem um volume pequeno alguns elementos não foram fabricados, a maquete tátil da Praça Mario Bernardi era apenas um módulo com diversos brinquedos em que o balanço não saiu durante a impressão, o escorregador e as "casinhas" ficaram totalmente sólidas. Foi utilizado para perfuração das rebarbas uma Furadeira e Impacto Bosh GSB 13 RE e utilização de mecanismos quentes para suavizar os locais ásperos para as crianças não se machucarem durante a tatilidade.

Concluindo, deveriam haver novos testes de produção das maquetes táteis, para que as crianças não se machucassem durante a tatilidade das mesmas e conseguissem entender melhor o mecanismo de comunicação. Assim então, foram produzidas mais duas maquetes táteis, projetadas no Software online Tinkercad.

O segundo projeto desenvolvido das maquetes, se constituiu por diversas peças de cada maquete, pensando em um processo de montagem, para assim, não haver rebarbas durante a impressão e as crianças conseguirem melhor tateá-las. Foram desenvolvidas quarenta e cinco peças entre as duas maquetes, necessitando um processo de montagem e colagem (Figura 05).

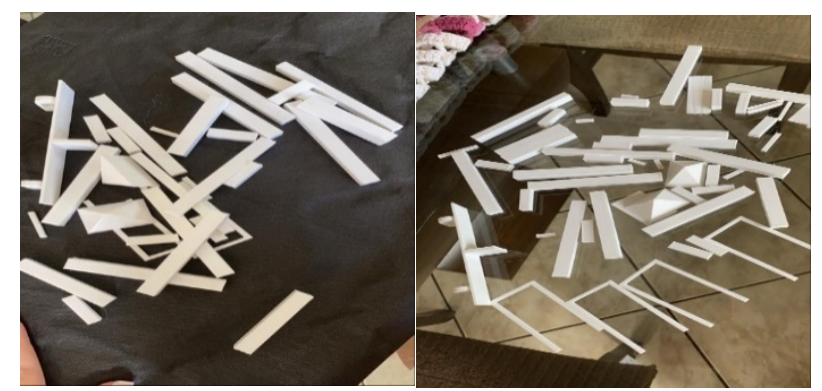

Figura 5. Maquete tátil desmontada. Fonte: Autora (2020). 
aplicadas em ambiente formal ${ }^{1}$, na escola, mas acabaram sendo aplicados em ambiente informal, e com auxílio dos responsáveis, nas casas dos participantes da pesquisa.

Foi elaborado um projeto de Playground com as diretrizes a partir das atividades aplicadas com o grupo de pesquisa que não foi colocado no artigo, havendo também uma etapa do trabalho de pesquisa que ficará para projetos futuros, a apresentação do projeto do Playground com um momento de feedback do Codesign durante o PC ao grupo da pesquisa que devido a pandemia deverá ser adiado, para ser realizado em ambiente formal futuramente.

Concluindo que este projeto de pesquisa concretizou novos métodos, ferramentas e recursos de Codesign de paisagismo em playgrounds infantis, no qual a partir dos métodos aplicados foi possível afirmar que o processo de Codesign com usuários auxilia no resultado final do projeto, tornando-o mais assertivo. Com testagem positiva das maquetes táteis aplicadas com as crianças participantes da pesquisa, que anteriormente não haviam testagem com crianças com deficiência visual.

Agradecimentos. Agradecemos a Associação Passofundense de Cegos APACE, as Escolas participantes e os entrevistados pela importante contribuição científica a este trabalho de pesquisa; a Fundação IMED; o Núcleo de Inovação e Tecnologia em Arquitetura e Urbanismo (NITAU) do Programa de Pós-graduação em Arquitetura e Urbanismo da IMED (PPGARQ/IMED); o Conselho Nacional de Desenvolvimento Científico e Tecnológico - CNPq; e a Fundação de Amparo à Pesquisa do Rio Grande do Sul - FAPERGS. O presente trabalho foi realizado em parte com apoio da Coordenação de Aperfeiçoamento de Pessoal de Nível Superior - Brasil (CAPES) - Código de Financiamento 001.

\section{Referências}

Assis, Pedro. (2018). O que é arquitetura colaborativa e como ela está mudando as relações no mercado de trabalho. Disponível em: https://www.archdaily.com.br/br/893003/o-que-e-arquitetura-colaborativa-e-comoela-esta-mudando-as-relacoes-no-mercado-de-trabalho. Acesso em: 29 mar. 2020.

Brasil. Lei no. 13.146/15. Disponível em: http://www.planalto.gov.br/ccivil_03/_ato20152018/2015/lei/l13146.htm Acesso em: 26 abr. 2020 
